\title{
ANALISA DAN PERANCANGAN ISTEM INFORMASI DISPOSISI SURAT PADA BIDANG LALU LINTAS DINAS PERHUBUNGAN KOTA BATAM
}

\author{
Okta Veza, Abdul Rohmad Basar, Muhammad Setyo Nugroho \\ STT Ibnu Sina Batam \\ Program Studi Teknik Informatika, STT Ibnu Sina, Batam \\ e-mail: Okta@stt-ibnusina.ac.id,basar@stt-ibnusina.ac.id
}

\begin{abstract}
Abstrak
Analisa dan Perancangan Sistem Informasi Disposisi Surat Pada Bidang Lalu Lintas Dinas Perhubungan Kota Batam bertujuan untuk membantu tugas pokok dan fungsi pada Bidang Lalu Lintas dalam pelaksanan tugas yang tertuang pada lembar disposisi dan terimplementasikanya dalam perangkat lunak, yang sebelumnya masih manual dalam pendisposisian dan penginputan hasil dari disposisi tersebut. Maka dalam penyusunan sistem informasi pada Bidang Lalu Lintas ini menggunakan pemodelan UML dengan bahasa pemograman PHP, MYSQL, APPSERV dan berbasis Web Mobile. Hasil dari analisa dan perancangan sistem informasi ini terbangunya prototype pendisposisian surat ke Bidang Lalu Lintas dalam perangkat lunak sehingga dapat meudahkan dalam pendelegasian tugas dan penerimaan hasil dari tugas dalam disposisi.
\end{abstract}

Kata kunci- Kata kunci: Sistem Informasi, php, mysql, appserv, web mobile

\begin{abstract}
Analysis and Design of Information Systems in the Traffic Field of Batam Transportation Department aims to assist the main tasks and functions in the Field of Traffic in the implementation of the tasks contained in the disposition sheet and implemented in the software, previously still manual in the posisisisian and inputting the results of the disposition. So in the preparation of information systems in the Field of Traffic is using UML modeling with programming languages PHP, MYSQL, APPSERV and Web-based Mobile. The result of the analysis and design of this information system is the prototype of the letter's disposition to the Traffic Field in the software so that it can facilitate the delegation of tasks and acceptance of the results of the task in disposition.
\end{abstract}

Keyword: Information System, php, mysql, appserv, web mobile

\section{PENDAHULUAN}

Undang-undang Nomor 22 tahun 2009 Tentang Lalu Lintas dan Angkutan Jalan bagian Poin $\mathrm{C}$ bahwa perkembangan lingkungan strategis nasional dan internasional menuntut penyelenggaraan lalu lintas dan angkutan jalan sesuai dengan perkembangan ilmu pengetahuan dan teknologi, otonomi daerah, serta akuntabilitas penyelenggaraan Negara. Aparatur Negara Reformasi Birokrasi yang tersusun didalamnya Organisasi pemerintahan terdapat tugas pokok dan fungsi yang harus dapat dilaksanakan sudah saatnya dituangkan dalam bentuk sistem informasi yang akuntabel dan berkesinambungan guna penyampaian informasi bagi pejabat dan staf. Khususnya Dinas Perhubungan Kota Batam pada Bidang Lalu lintas dengan sistem informasi 
sehingga mempermudah capaian kinerja selanjutnya dapat dipublikasikan ke masyarakat guna memberikan informasi dan edukasi, sehingga terwujud pelayanan prima dan pembangunan Kota Batam yang lebih baik dan berkesinambungan.

Tugas pokok dan fungsi Bidang Lalu Lintas terbagi dalam 3 (tiga) seksi yakni seksi Manajemen dan Rekayasa Lalu Lintas, seksi Keselamatan Lalu Lintas, dan seksi Pengawasan dan ketertiban Lalu Lintas. Pelaksanaan tugas pokok dan fungsi Bidang Lalu Lintas saat ini masih tertulis secara manual dalam kertas dan tersimpan dalam bundle gungyu dan belum tersusun secara sistematis antara surat masuk dan surat keluar diantara seksi-seksi di Bidang Lalu Lintas.

Analisa dan rancangan sistem informasi Bidang Lalu Lintas yang diimplementasikan menjadi perangkat lunak diharapkan dapat mempermudah dalam penyampaian ,pelaporan, penyimpanatugas pokok dan fungsi secara berkelanjutan guna mengoptimalkan kinerja yang diamanahkan, sehingga setiap staf yang ditugaskan di Bidang Lalu Lintas dapat memahami jenis pekerjaan, cara pelaporan pekerjaan, cara menyampaikan informasi kepada pimpinan, penyimpanan dan penjelasan kepada masyarakat.

Berdasar pada fakta dilapangan yang dituangkan pada latar belakang masalah penulis mengajukan Judul Analisa dan Perancangan Sistem Informasi Disposisi Surat Pada Bidang Lalu Lintas Dinas Perhubungan Kota Batam ,diharapkan dengan dibangunanya sistem informasi tersebut dapat membantu pelaksanaan tugas dalam disposis bagi para pejabat dan staf di Bidang Lalu Lintas yang tersaji dalam bahasa program juga sebagai kerangka pengembangan sistem selanjutnya

\section{Rumusan Masalah}

Bidang Lalu Lintas Dinas Perhubungan Kota Batam dengan permasalahan tersebut diatas maka dapat ditarik rumusan masalah sebagai berikut :

1. Bagaimana menganalisa dan merancang sistem informasi pada Bidang Lalulintas Kota Batam?

2. Bagaimana implementasi rancangan tersebut menjadi perangkat lunak sehingga dapat digunakan sebagai kerangka pengembangan sistem informasi selanjutnya?

\section{Tujuan}

Dengan tersusunya laporan ini penulis mempunyai tujuan

1. Menganalisa dan merancang sistem informasi yang berhubungan dengan diposisi surat pada Bidang lalulintas Dinas Perhubungan Kota Batam.

2. Mengimplementasikan rancangan menjadi perangkat lunak guna kerangka pengembangan sistem informasi selanjutnya.

\section{Metode Penelitian}

\section{Data Primer}

Data primer adalah data yang diperoleh langsung dari sumbernya, yaitu dengan melakukan observasi terhadap informasi yang dijadikan tempat penelitian. Data primer diperoleh dari daftar surat masuk dan disposisi ke bidang Lalu Lintas di Dinas Perhubungan Kota Batam. dibawah ini adalah data yang akan digunakan:

1. Sistem pendisposisian surat ke Bidang Lalu Lintas.

2. Sitem Penyampaian dan pelaporan hasil tugas yang tertuang dari lembar disposisi

\section{Data Sekunder} Bidang Lalu Lintas.

Data sekunder adalah data yang diperoleh dari buku-buku literatur, jurnal, dokumendokumen, laporan, dan lain-lain. Data tersebut didapat dari Perpustakaan STT Ibnu Sina Batam, Dinas Perhubungan Kota Batam, dan browsing di internet, di bawah ini data yang digunakan:

1. Struktur Organisai Dinas Perhubungan Kota Batam

2. Lembar disposisi

3. Contoh surat masuk ke Bidang Lalu Lintas 


\section{Hasil dan Pembahasan}

\section{Analisa Masalah}

Selama penulis menganalisa sistem yang berjalan pada Bidang Lalu Lintas Dinas Perhubungan Kota Batam maka penulis menentukan masalah dalam setiap proses pengumpulan data dan proses penyerahan yang masih berbentuk manual serta waktu yang dibutuhkan terkendala oleh beberapa masalah di antaranya:

1. Pendelegasian tugas dan penginputan hasil penugasan yang tertuang dalam lembar disposisi masih tertulis secara manual yang tidak terstruktur.

2. Perlu adanya sistem informasi guna kelancaran dan keberlangsungan penyelesaian tugas dalam disposisi pada Bidang Lalu Lintas Dinas Perhubungan Kota Batam.

\section{Proses Bisnis}

Proses bisnis untuk disposisi meliputi beberapa proses yang saling ketergantungan satu sama lain meliputi, tugas yang akan dilaksanakan bagian masing-masing dan laporan tugas. Sistem informasi Dinas Perhubungan Kota Batam mutlak menjadi kebutuhan yang utama dalam menjalankan operasional bisnisnya.

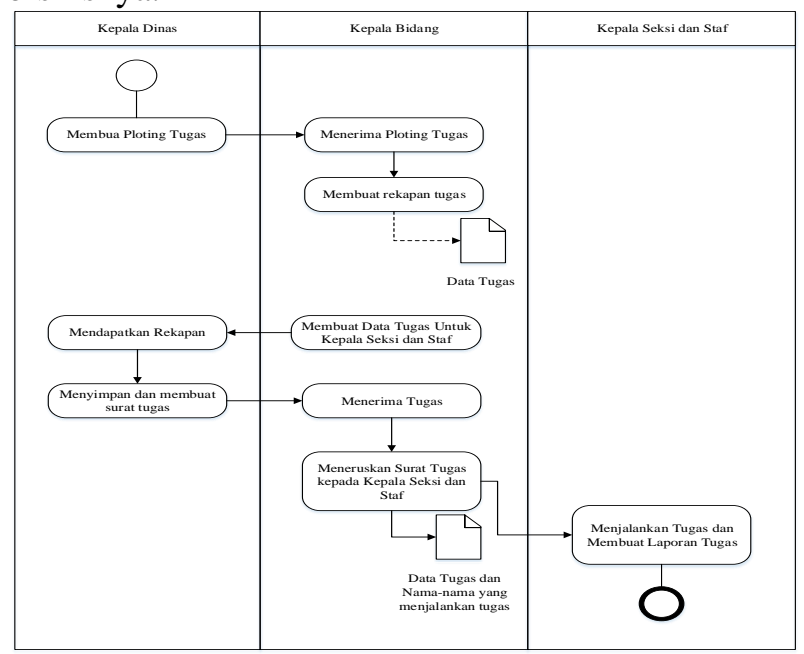

Perancangan UML (Unifed Modelling Language)

1. Use Case Diagram

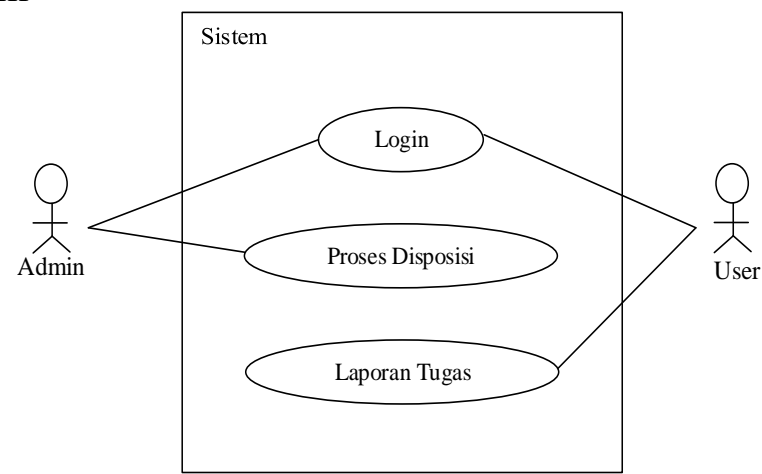

Use Case Diagram Sistem Disposisi 
Analisa Dan Perancangan Istem Informasi Disposisi Surat Pada Bidang Lalu Lintas Dinas Perhubungan Kota Bata

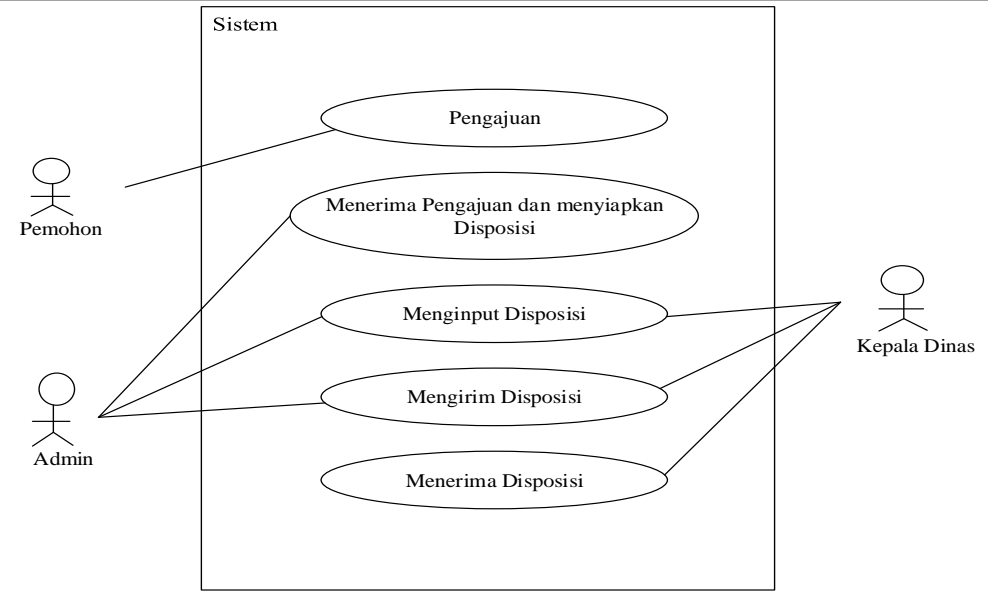

Use Case Diagram Permohonan

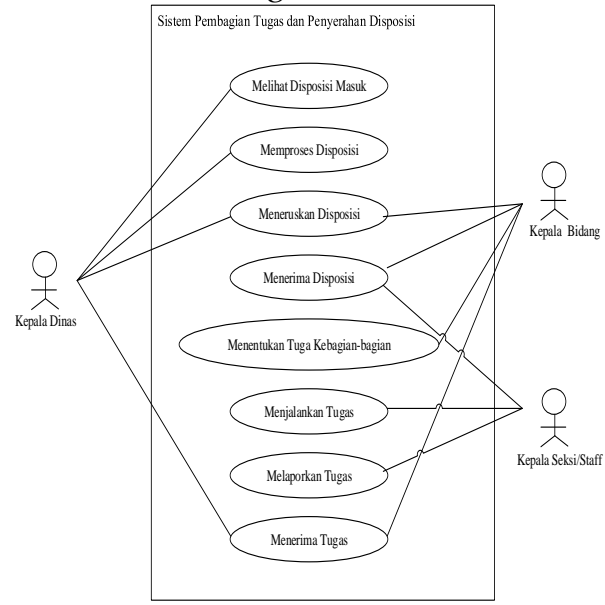

Use Case Diagram Pembagian dan Penyerahan

2. Activity Diagram

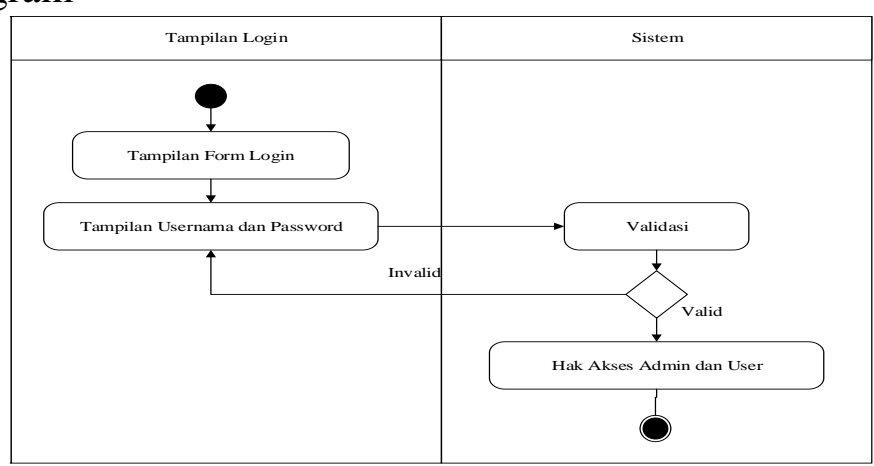

Activity Diagram Login 


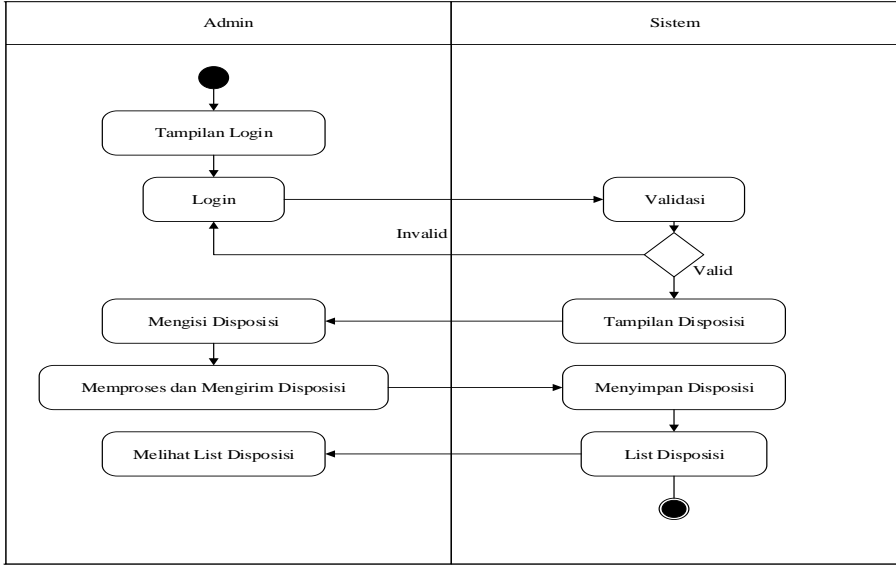

Activity Diagram Input Admin

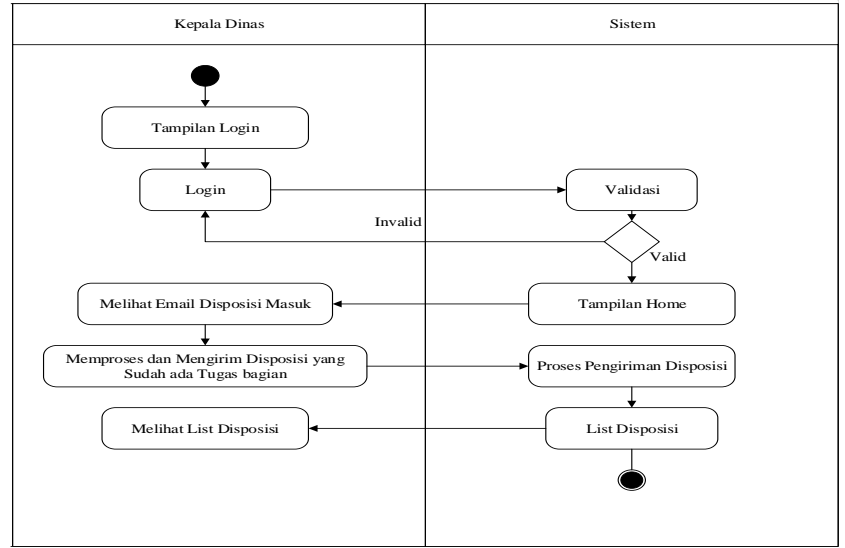

Activity Diagram Bagian Kepala Dinas

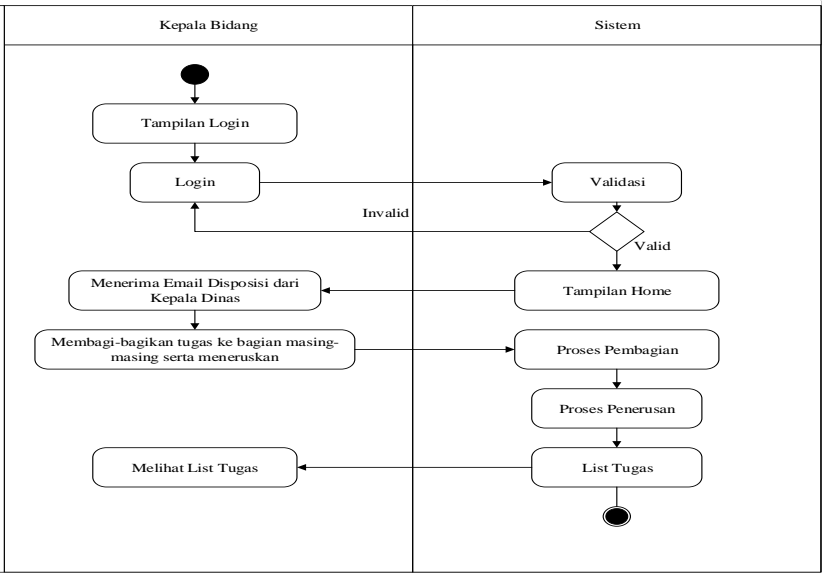

Activity Diagram Bagian Kepala Bidang 


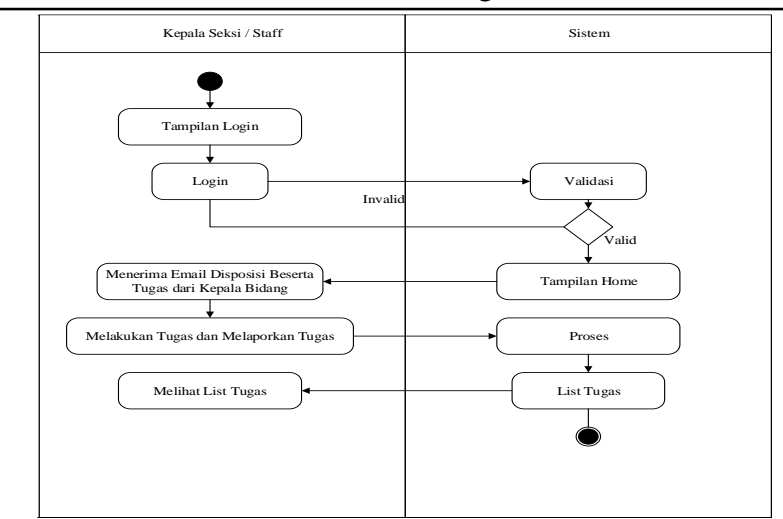

Activity Diagram Bagian Kepala Seksi dan Staf
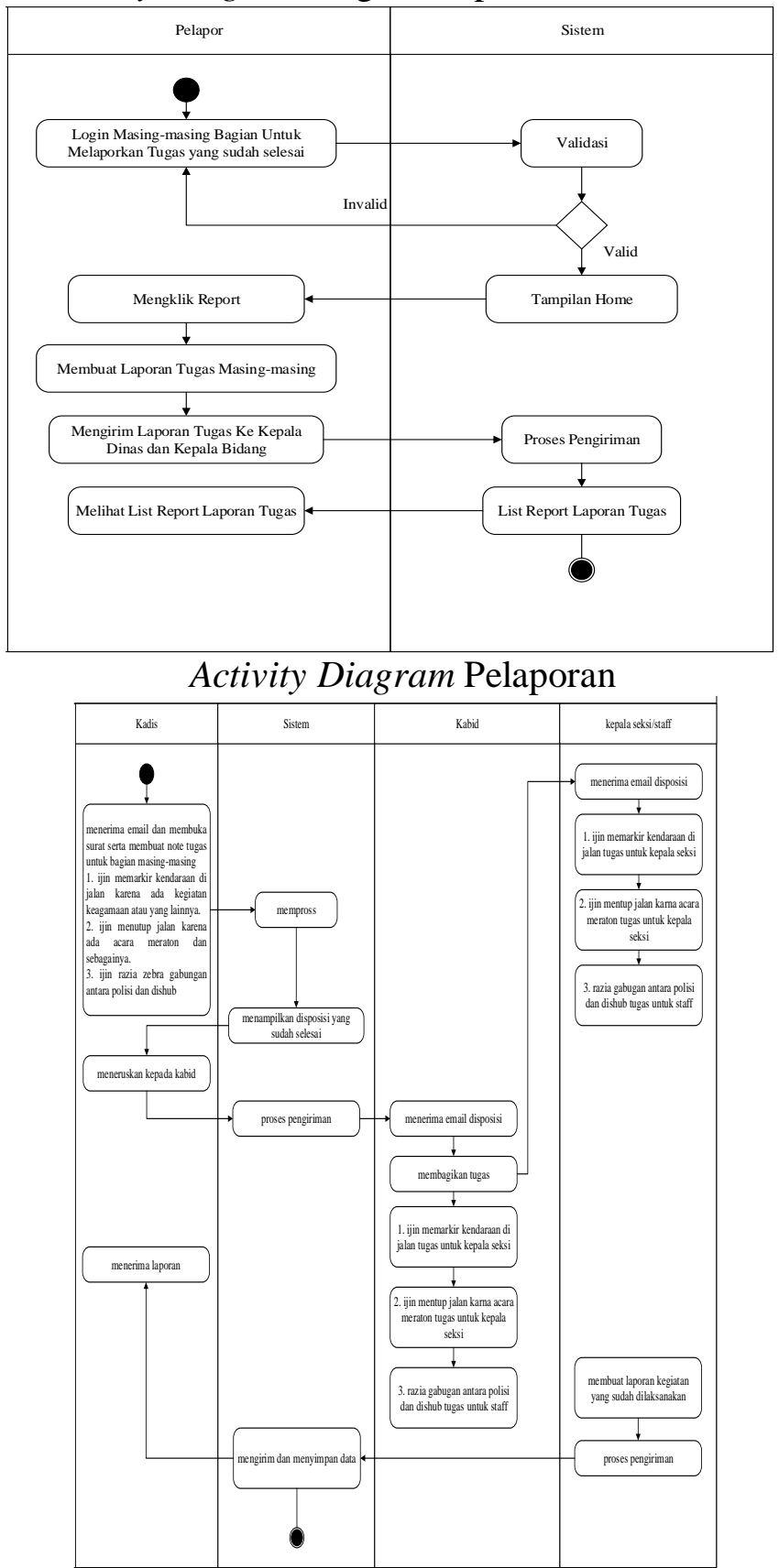

Activity Diagram Kegiatan Dishub 
3. Sequence Diagram

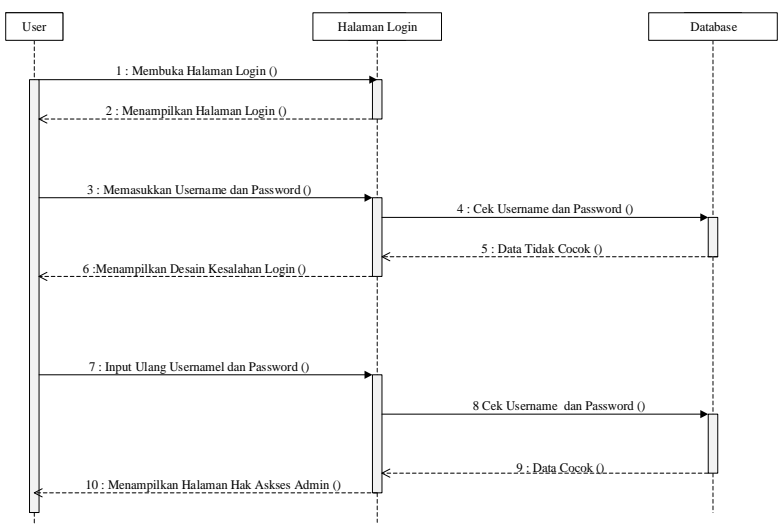

Sequence Diagram Tampilan Login

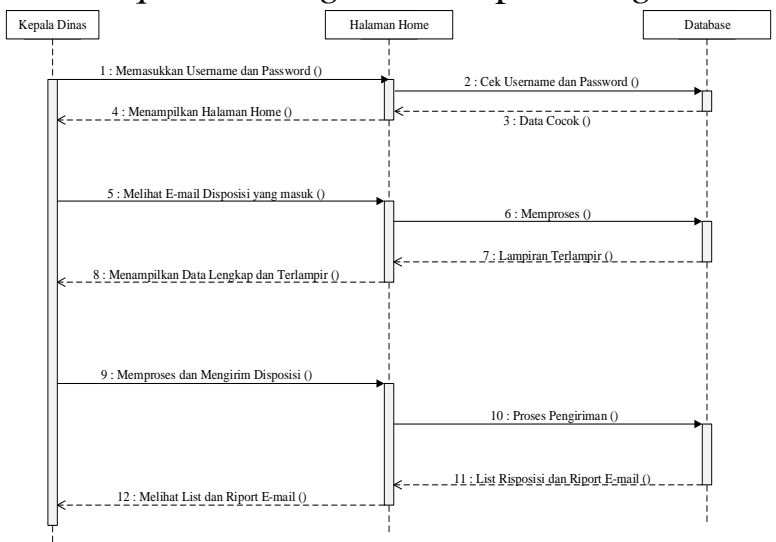

Sequence Diagram Kepala Dinas

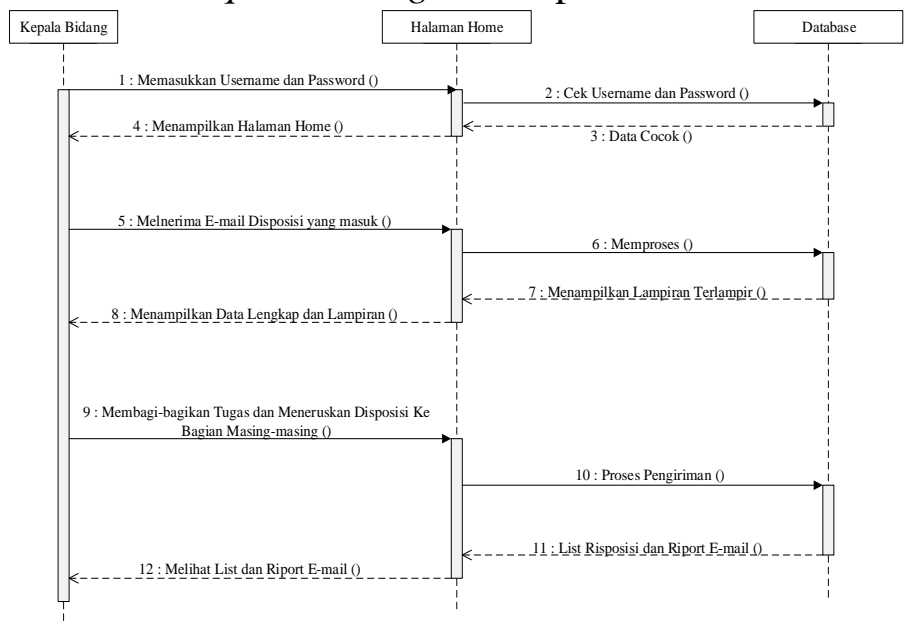

Sequence Diagram Kepala Bidang 


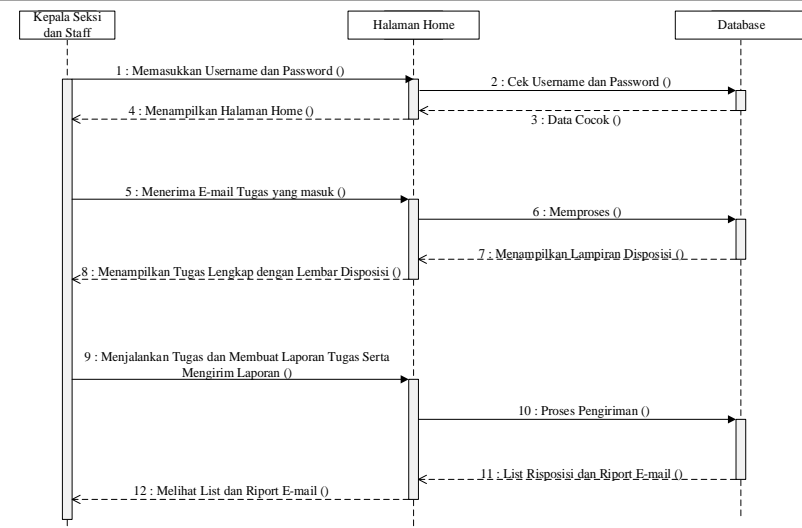

Sequence Diagram Kepala Seksi dan Staff

\section{Class Diagram}
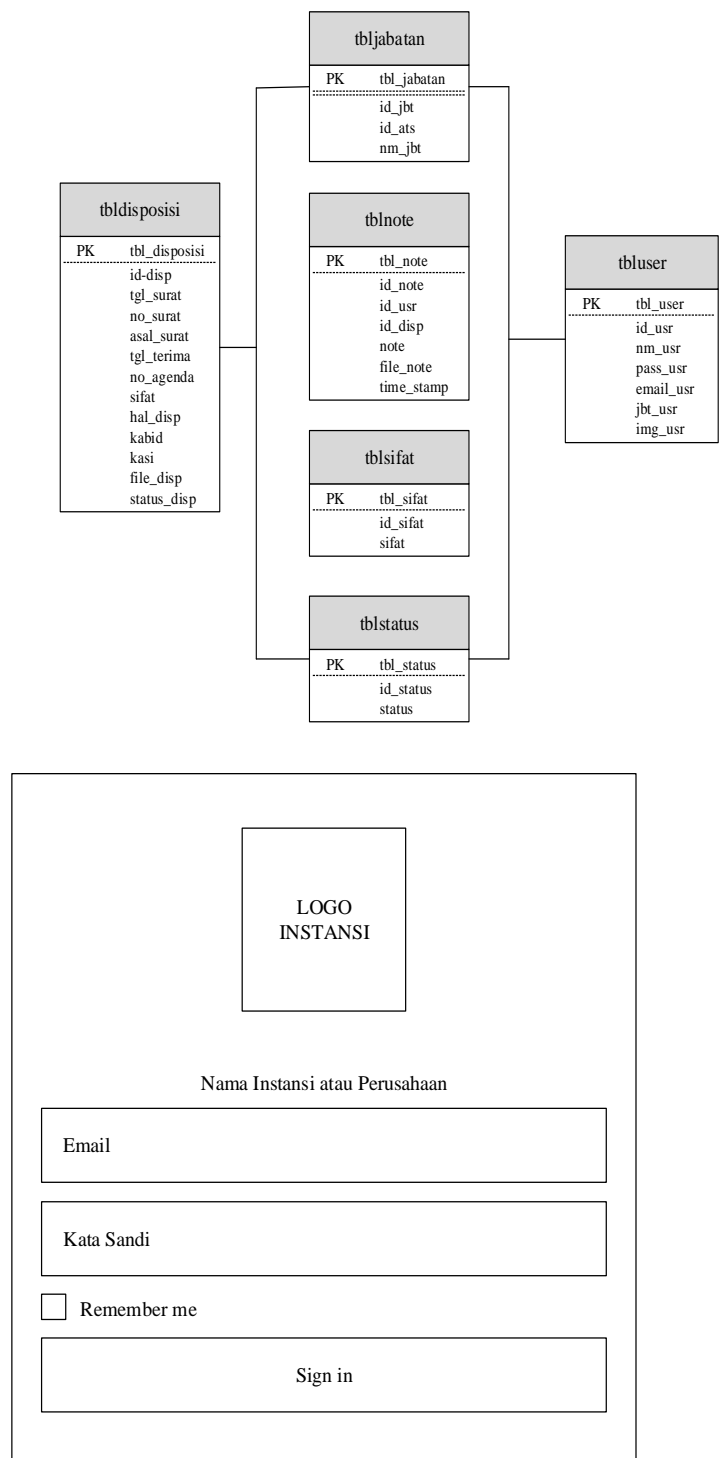

Tampilan Login 


\begin{tabular}{|c|c|c|c|c|c|c|c|c|c|}
\hline \multicolumn{3}{|c|}{ Nama Instansi / Perusahaan } & \multirow{2}{*}{\multicolumn{3}{|c|}{ entries }} & & \multicolumn{3}{|r|}{ Logout } \\
\hline \multirow{3}{*}{$\begin{array}{l}\text { Data Pengguna } \\
\text { Pengguna } \\
\text { Jabatan }\end{array}$} & Show & 10 & & & & \multicolumn{4}{|c|}{ Search: } \\
\hline & No & & Gambar & Nama Pengguna & Email & Jabatan & \multicolumn{3}{|c|}{ Action } \\
\hline & No & Gambar & & Nama Pengguna & Email & Jabatan & Edit & Dekete & Ubah Sandi \\
\hline & No & Gambar & & Nama Pengguna & Email & Jabatan & Edit & Dekete & Ubah Sandi \\
\hline & No & Gambar & & Nama Pengguna & Email & Jabatan & Edit & Dekete & Ubah Sandi \\
\hline & No & Gambar & & Nama Pengguna & Email & Jabatan & Edit & Dekete & Ubah Sandi \\
\hline & No & Gambar & & Nama Pengguna & Email & Jabatan & Edit & Dekete & Ubah Sandi \\
\hline & \multicolumn{9}{|c|}{ Showing 1 to 2 of 2 enteris } \\
\hline & + & & & & & & Previou & 1 & Next \\
\hline
\end{tabular}

Tampilan Pengguna

\begin{tabular}{|l|}
\hline Tambah Pengguna \\
\begin{tabular}{|l|l|}
\hline Pilih File & Tidak ada file yang dipilih \\
\hline Nama Pengguna & \\
\hline Email Pengguna & \\
\hline Pilih Jabatan Pengguna & Satal \\
\hline
\end{tabular} \\
\hline
\end{tabular}

\section{Tampilan Tambah Pengguna}

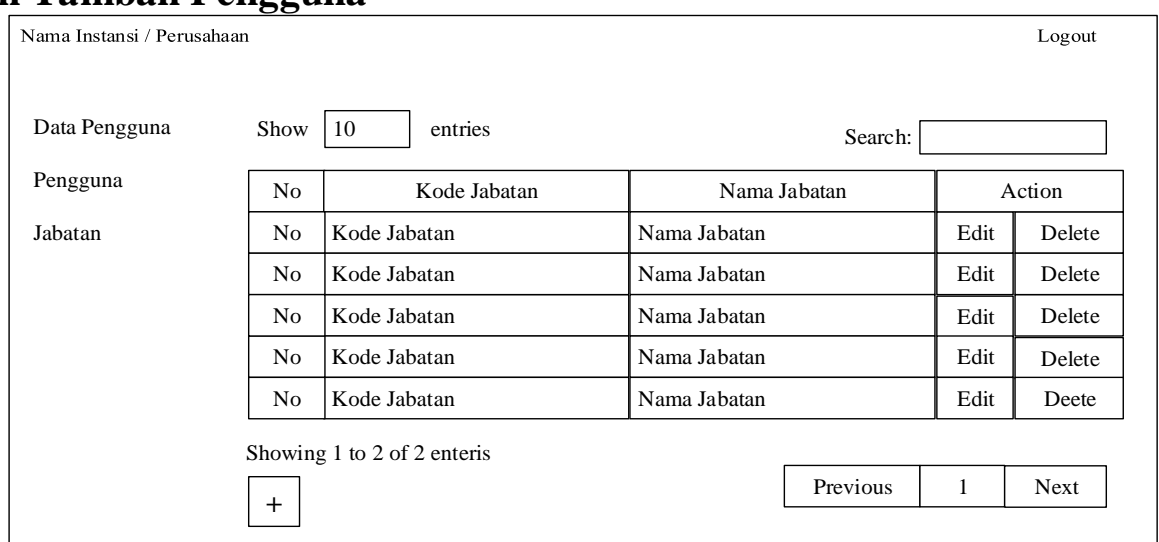

\section{Tampilan Jabatan}

\begin{tabular}{|l|l|}
\hline Tambah Jabatan & X \\
\hline Pilih Kabid & \\
\hline Nip & \\
\hline Nama Admin & Batal \\
\hline Gelar Admin & Simpan \\
\hline \multicolumn{2}{|c|}{} \\
\hline
\end{tabular}


Tampilan Tambah Jabatan

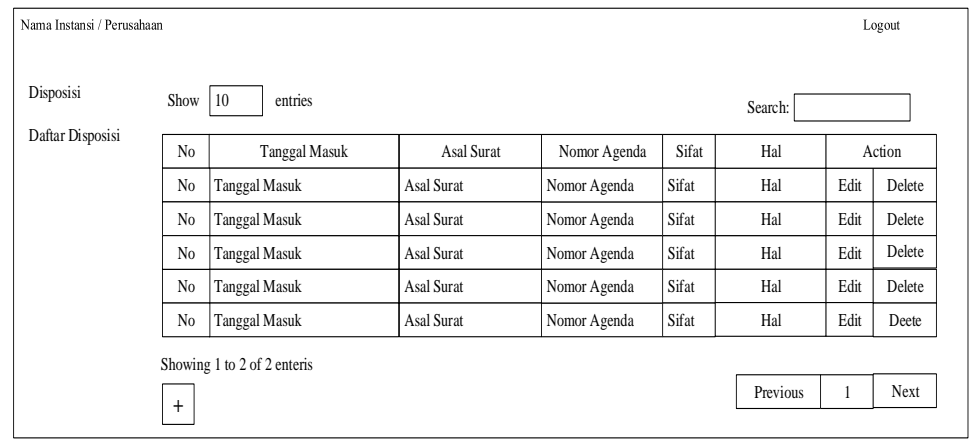

\section{Tampilan Daftar Disposisi}

\begin{tabular}{|l|l|}
\hline Keluar halaman Admin \\
\hline Yakin Akan Keluar Halaman Admin? \\
\hline \multicolumn{1}{|c|}{ Batal } \\
\hline
\end{tabular}

Tampilan Logout

\begin{tabular}{|l|l|}
\hline Tampilan Disposisi \\
\hline Asal Surat \\
\hline No Surat \\
\hline Tanggal Masuk \\
\hline Tanggal Harus di Laksanakan \\
\hline No Agenda & \multicolumn{1}{|c|}{ Tampilan Edit } \\
\hline Sangat Segera $\bigcirc$ Segera $\bigcirc$ Rahasia \\
\hline \multicolumn{1}{|c|}{} \\
\hline
\end{tabular}

Tampilan Disposisi

Implementasi

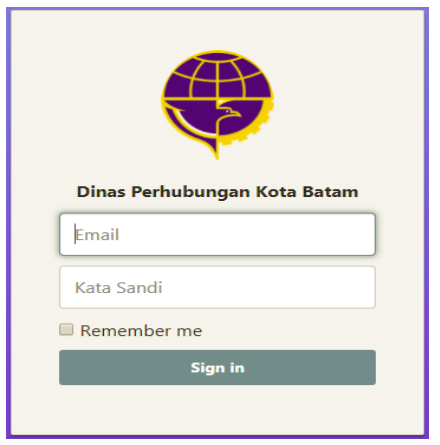

Login Dishub 


Keluar Halaman Admin
Yakin Akan Keluar Halaman Admin?
\begin{tabular}{|l|l|l|}
\hline \multicolumn{1}{|c|}{ Logout Dishub } & Batal & Kelu \\
\hline Tambah Pengguna & $\times$ \\
\hline Pilih File Tidak ada file yang dipilih & \\
\hline Nama Pengguna & Batal & simpan \\
\hline email Pengguna & \\
\hline Pilih Jabatan Penqquna & & \\
\hline
\end{tabular}

Tambah Pengguna

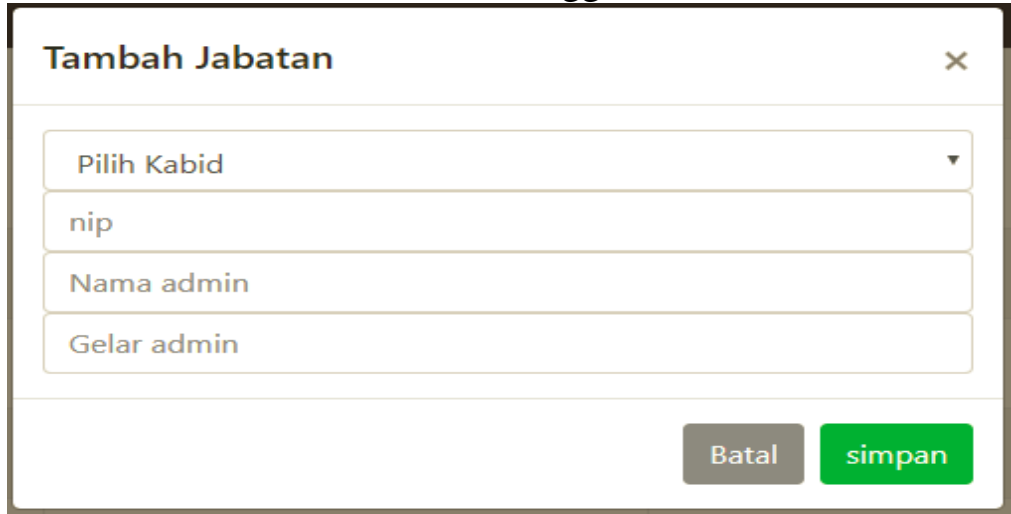

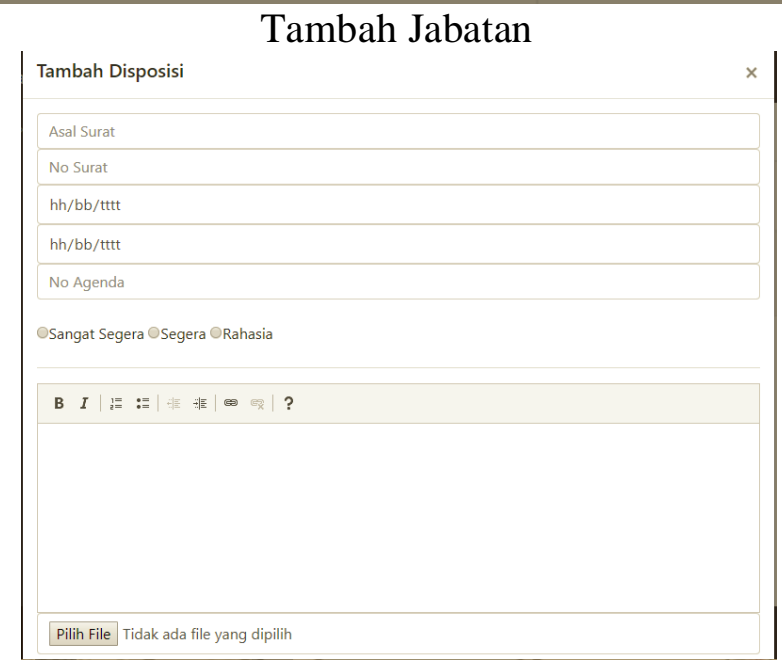

Tambah Disposisi 


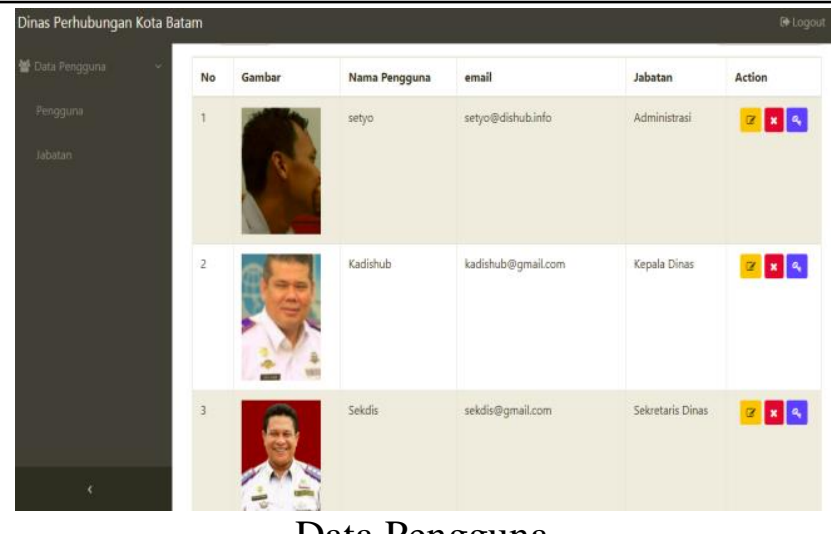

Data Pengguna

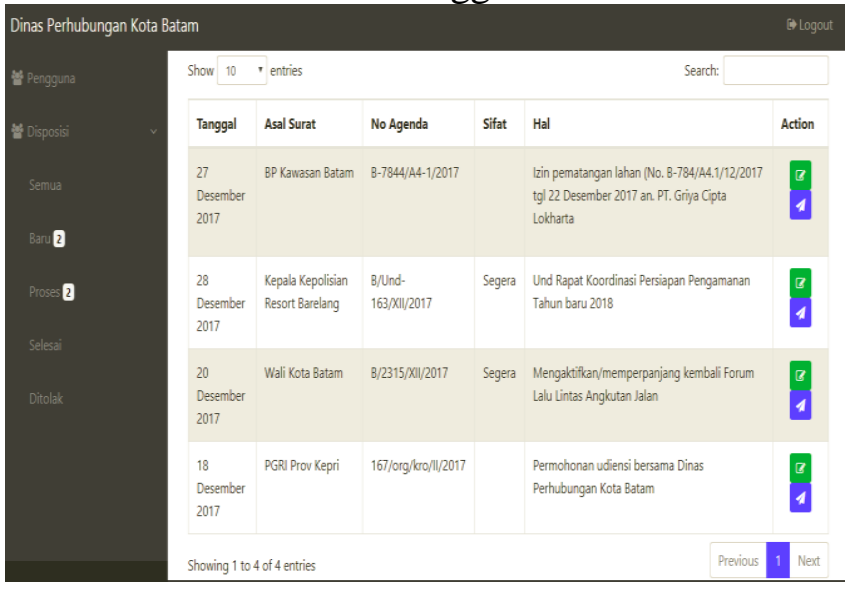

Kadishub Semua Surat Masuk dan Proses

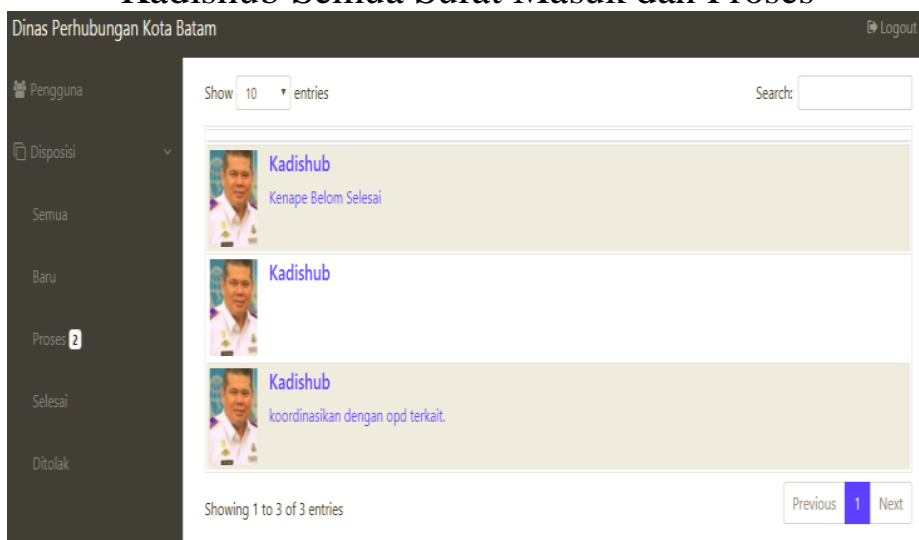

Kabid Lalin

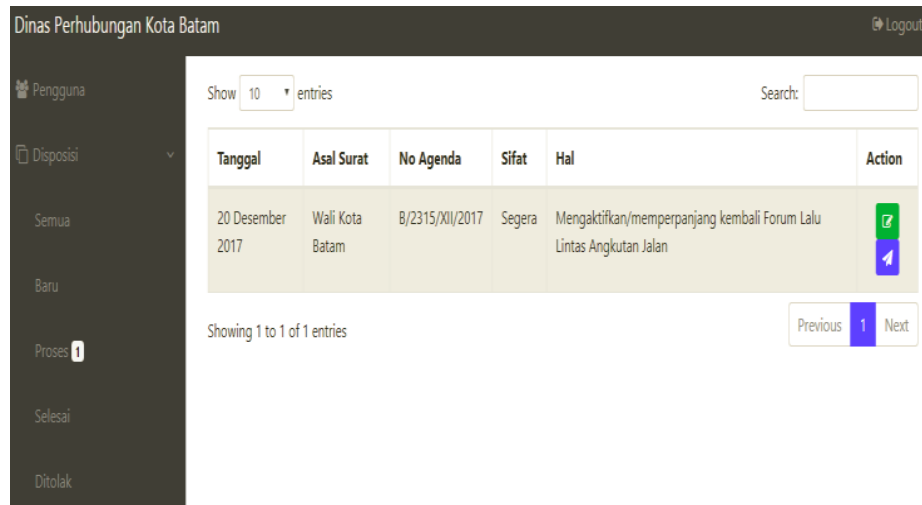

Kasi Manrek Tampilan Surat Proses 
Kesimpulan

\section{Kesimpulan Dan Saran}

Setelah proses bisnis disposisi Bidang Lalu Lintas Dinas Perhubungan Kota Batam tersusun, maka penulis dapat membuat suatu kesimpulan tentang keadaan yang terjadi. Berdasarkan penelitian yang telah dilakukan,maka dapat ditarik beberapa kesimpulan antara lain:

1. Hasil Analisa dan Perancangan Sistem Informasi Bidang Lalu Lintas Dinas Perhubungan Kota Batam yang selama ini masih berbentuk tulisan tangan dan tersimpan dalam bundle gungyu dapat dijalankan dengan bentuk perangkat lunak menggunakan metode kualitatif, diskriftif dengan pemodelan UML.

2. Implementasi rancangan menjadi perangkat lunak menggunakan PHP, MYSQL dan Web Mobile sehingga dapat memudahkan dalam pelaksanaan dan penyelesaian tugas yang tertuang dalam lembar disposisi, juga untuk kerangka pengembangan sistem informasi selanjutnya.

Saran

Adapun saran-saran yang dapat penulis berikan untuk penggunaan perangkat lunak Sistem Informasi Bidang Lalu Lintas Dinas Perhubungan Kota Batam serta untuk kerangka pengembangan sistem informasi selanjutnya sebagai berikut:

1. Hasil Analisa dan Perancangan Sistem Informasi Bidang Lalu Lintas Dinas Perhubungan Kota Batam masih dalam bentuk prototype sehingga memungkinkan untuk dikembangkan pada tahap selanjutnya.

2. Sistem Informasi saat ini hanya pada Bidang lalu Lintas Dinas Perhubungan Kota Batam, kedepan perlunya untuk dapat dikembangkan kesemua bidang dan seksi di Dinas Perhubungan Kota Batam.

\section{DAFTAR PUSTAKA}

Anisah (2017). Analisa dan Perancangan Sistem Informasi Administrasi Kepegawaian Pada Dinas Kebudayaan dan Pariwisata Provinsi Kepulauan Bangka Belitung. Jatisi, Vol. 1 No. 2 ww.mdp.ac.id/jatisi/vol-3-no2/6.\%20jurnal\%20Anisah.pdf

Anisya (2013). Aplikasi Sistem Database Rumah Sakit Terpusat Pada Rumah Sakit Umum (RSU) 'AISYIAH Padang Dengan Menerapkan Open Source (PHP-MYSQL). Jurnal Momentum ISSN: 1693-752x Vol. 15 No.2. Agustus 2013

Chindra Saputra (2017) Analisis dan Perancangan Sistem Informasi Administrasi Kependudukan Pada Desa Karang. Jurnal Manajemen Sistem Informasi Vol.2 No.3, September 2017 jurnalmsi.stikom db.ac.id/index.php/jurnalmsi/article/down load/107/83

Dharwiyanti, (2016). “ Pengantar Unified Modeling Language (UML)". Ilmukomputer 2003. JTIBSI, Volume 01, Nomor 01, Oktober 2016

Dewi Rosmala (2007) Pemodelan Proses Bisnis B2B Dengan BPMN (Studi Kasus Pengadaan Barang Pada Divisi Logistik), Seminar Nasional Aplikasi Teknologi Informasi 2007 (SNATI 2007) Yogyakarta, 16 Juni 2007. ISSN: 1907-5022

Eka Iswandi (2015) Sistem Penunjang Keputusan Untuk Menentukan Penerimaan Dana Santunan Sosial Anak Nagari Dan Penyalurannya Bagi Mahasiswa Dan Pelajar Kurang Mampu Di Kenagarian Barung-Barung balantai Timur. Jurnal TEKNOIF. Vol 3 No. 2 Oktober 2015. ISSN: $2338-2724$ 
Endra Krisna Putra (2016) Analisa dan Perancangan Sistem Reservasi Pemakaman Online Pemerintah Kota Bekasi.digilib.mercubuana.ac.id/manager/nl@file _skripsi_cover 810714488544.pdf .

Ganda Yoga Swara (2016) Rekayasa Perangkat Lunak Pemesanan Tiket Bioskop Berbasis Web. Jurnal TEKNOIF Vol. 4 No. 2 Oktober 2016, ISSN: 2338-2724.

Gata, Windu dan Gata, Grace (2013). Sukses membangun Aplikasi Penjualan dengan Java. Jakarta : Elex media Komputindo.

Hanif Al Fatta, Robert Marco (2015) Analisis Pengembangan Dan Perencangan Sistem Informasi Akademik Smart Berbasis Cloud Computing Pada Sekolah Menengah Umum (SMUN) Di Daerah Istimewa Yogyakarta.

Ejournal.amikompurwokerto.ac.id/index.php/telematika/article/download/396/364

Harison, Ahmad Syarif (2016) Sistem Informasi Geografis Sarana Pada Kabupaten Pasaman Barat. Jurnal TEKNOIF. Vol. 4 No.2 Oktober 2016, ISSN: 2338-2724

Iswandy, E. (2016). Analisa Dan Perancangan Sistem Informasi Penagihan Purchasing Order Custamer Studi Kasus Pada CV. Vertical Cipta Relasi Padang Dengan Metode Centralized Processing, Jurnal TEKNOIF, Vol.4(2), ISSN: 2338-2724

Jogiyanto (2005). Analisis \& Desain Sistem Informasi, Andi Offset Yogyakarta.

Mcleod, Jr., Raymond and Schell, George P (2007). Management Information System, 10 Edition. New Jersey : Prentice Hall.

Mulyadi (2001). Sistem Akuntasi. Edisi III. Jakarta: Salemba

Peraturan Wali Kota, Nomor 28 Tahun 2016, tentang Tugas Pokok dan Fungsi Dinas Perhubungan

Okkita Rizan, Hamidah, Indah Yuniarti (2017). Analisis dan Perancangan Sistem Informasi Perkawinan Non-Muslim Pada Dinas Kependudukan dan Catatan Sipil Pangkalpinang, Jurnal Teknosi, Vol 03, No. 01

Ropianto, M. (2016). Pemahaman Penggunaan Unified Modelling Language, Jurnal Teknologi IBSI, Vol.1(1)

Setyabudhi, A. L. (2017). Perancangan Sistem Informasi Pengolahan Data Absensi dan Pengambilan Surat Cuti Kerja Berbasis Web. JR: JURNAL RESPONSIVE Teknik Informatika, l(1).

Suci Lestari (2017). Analisa dan Perancangan Sisem Informasi Pengolahan Data Penduduk di Kantor Kecamatan Sungaiselan Bangka Tengah. Jurnal SIFOM. Lppm.atmaluhur.ac.i/wp content/iploads/.../jurnal_1022500164_SuciLestari.pdf

Veza, O. (2017). Perancangan Sistem Informasi Inventory Data Barang Pada Pt. Andalas Berlian Motors (Studi Kasus: PT Andalas Berlian Motors Bukit Tinggi). Jurnal Teknik Ibnu Sina JT-IBSI, 2(2). 